\title{
The Most Important Cog in the Machine: Business Analysis and 5S Implementation in an Engineering Company
}

\author{
Matthew Worthington NIS Ltd., United Kingdom Margarita Georgieva \\ Advanced Engineering, Blackpool and The Fylde College, United Kingdom \\ Andrew Heaton \\ Advanced Engineering, Blackpool \& The Fylde College, United Kingdom \\ Abdelrahman Abdelazim \\ Advanced Engineering, Blackpool and The Fylde College, United Kingdom
}

\begin{abstract}
The focus of this paper is the $5 \mathrm{~S}$ process, incorporating a real working example of how this method can positively affect a business in terms of managing change and continuous improvement. The benefits that $5 \mathrm{~S}$ implementation can bring to a manufacturing business focus on every-day work with a holistic approach that intends to bring order both in the material environment and in the ethical values that support it. There are many factors that should be addressed when introducing $5 \mathrm{~S}$ into a company, including some less tangible ones like moral and ethical principles, environmental factors, sustainability, and risk management. The backgrounds of the project featured in this work is in the field of nuclear waste management. The development of $5 \mathrm{~S}$ practices are significant to this field because the methodology is known to increase safety and improve overall performance. However, it is also important to analyse what other aspects $5 \mathrm{~S}$ could impact in an engineering company in this business. This work will therefore investigate the wider aspects of engineering management practice before delving into more specific questions on manufacturing process improvement with a particular focus on the impact $5 \mathrm{~S}$ will have on workshop organisation and changing operator and technician culture. This will include a discussion of an industry relevant project and how $5 \mathrm{~S}$ has impacted it. The project in question is entitled Soffit Plate Project and is a batch production project where a quantity of 282 Soffit plates are assembled with over 100 components in each plate. In total there are thousands of components that need to be managed throughout the contract with added paperwork and manufacturing process management as required. The work evidences that a normal approach would not be sufficient or sustainable for profitability and that $5 \mathrm{~S}$ should be implemented from the beginning. The discussion focuses on the implementation of $5 \mathrm{~S}$ and its effect on engineering business management.
\end{abstract}

Keywords: 5S, introducing lean, lean manufacturing, process improvement, kaizen, SWOT, McKinsey 7S

DOI: $10.7176 /$ IEL/11-2-04

Publication date: June $30^{\text {th }} 2021$

\section{Introduction}

$5 \mathrm{~S}$ as a lean manufacturing approach can be seen as a framework intending to shape workplace management and to add a dimension to engineering project management. $5 \mathrm{~S}$ can be easily borrowed from its lean contexts and integrated as a standalone methodology within any project management approach as a means of preserving order and systematisation, or for the sake of standardising processes and procedures. (Viranda et al.) The advantage of $5 \mathrm{~S}$ lies in its agility and on its impact on safety management (Sukdeo, 2017), risk reduction and overall quality improvement as shown in a number of studies.

The practice of $5 \mathrm{~S}$ aims to embed the values of organisation, consistency, neatness, cleanliness, standardisation and discipline into the workplace (Osada, 1991). In Japan, 5S practice was initiated in the manufacturing sector and then extended to other industries and services sectors. The Toyota Production System provides a well-known example of 5S principles in practice. (Kobayashi et al, 2008) Some scholars (Kobayashi et al, 2006) imply that $5 \mathrm{~S}$ receives focus on specific applications only as opposed to being adapted in their holistic meaning, and while $5 \mathrm{~S}$ can be a universal approach, only a total of 84 Japanese organisations publicly describe $5 \mathrm{~S}$ on their organisational web sites (Kobayashi et al, 2008). In addition to that, Douglas (2002) and Ho et al (1995) both suggest that $5 \mathrm{~S}$ is underutilised by Western organisations. Whether this is a matter of corporate vision or a more philosophical approach to engineering company organisation, a review of the literature on $5 \mathrm{~S}$ implementation does reveal a rift between East and West, where India, China, Japan as well as the Middle East and parts of South America seem to more readily focus on strict $5 \mathrm{~S}$ implementation, whether by integrating it within lean approaches or other existing project management methods.

Womack, Jones and Roos (2007) believe that the fundamental ideas of lean production are universal and applicable anywhere by anyone, and that many non-Japanese companies have already learned this. An overarching review of $5 \mathrm{~S}$ principles utilised across industry reveals (Vipulkumar C. Patel et al, 2014) that engineering companies tend to prefer quick implementation of $5 \mathrm{~S}$, rather than full implementation of lean or six sigma as a 
holistic approach. It appears that $5 \mathrm{~S}$ is seen as a quicker and easier method to make noticeable and impactful changes without the added extra difficulty of thorough process and operations overhaul that may be required when moving to Lean Six Sigma throughout. The buy-in that can be obtained for a 5S project may, however, lead to a wider adoption of lean toolkits, eventually moving to Lean Six Sigma.

This paper documents the implementation of $5 \mathrm{~S}$ at an engineering company whilst incorporating business analysis into the process.

\subsection{Company Background and Motivation}

NIS Ltd. provide bespoke engineering solutions to the nuclear industry.

NIS Ltd. have decided to introduce kaizen (continuous improvement), and a lean mindset in the company through a soft and non-intrusive approach. $5 \mathrm{~S}$ has been selected for this purpose and implemented through an adapted kaizen tactic which involved traditional business modelling to understand current state and approach it with continuous improvement goals. Before the project initiation, a review of $5 \mathrm{~S}$ implementation examples has been conducted to enrich lessons learned.

\subsection{Project Background - Soffit Plate Project}

The project which is subject to this study is entitled Soffit Plate Project. It is a batch production project where a quantity of 282 soffit plates. (Figure 1) Each plate consists of over 100 components which need to be assembled. In total, there are thousands of components throughout the contract. All components and the final assembly need supporting paperwork to accompany the manufacturing process.
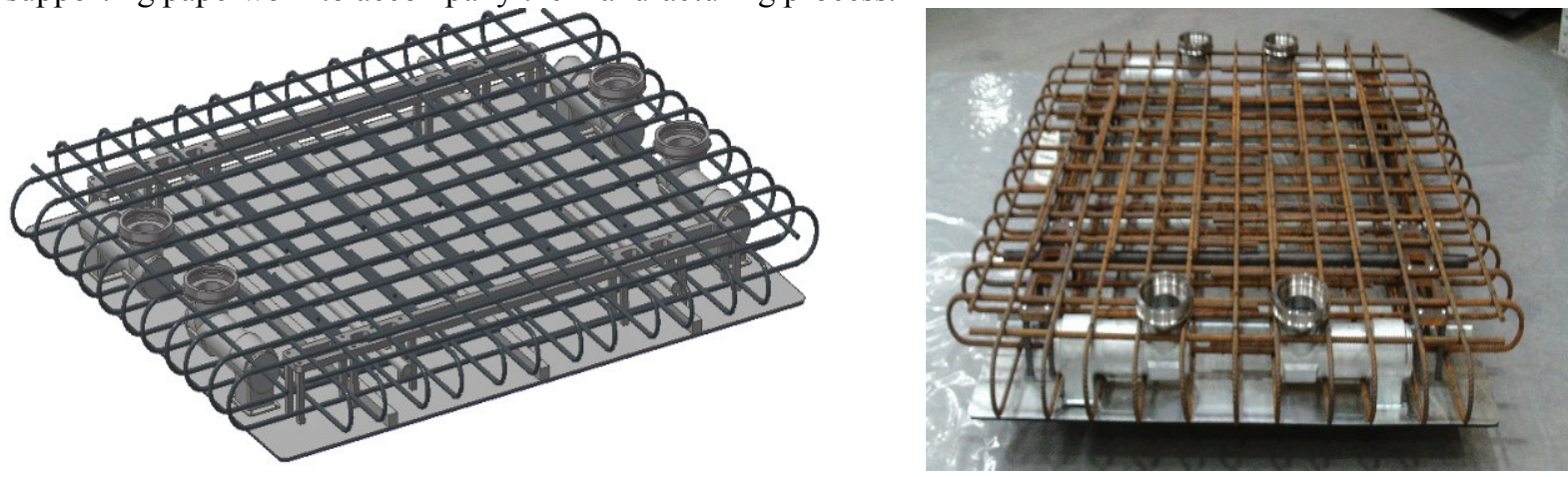

Figure 1 Design of a soffit plate and a soffit plate sample

The soffit plates will then be placed within concrete box packages (Figure 2), intended for the storage of nuclear waste.

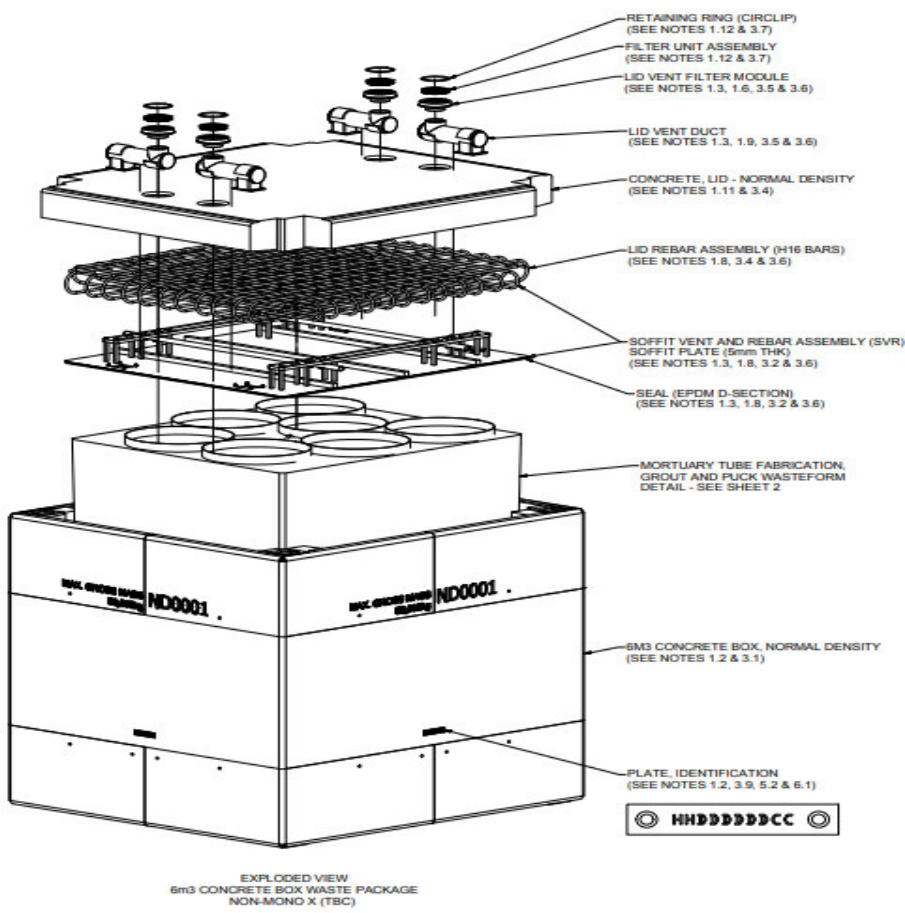

Figure 2 Design of a concrete waste storage box, indicating the position of the soffit plate 
The soffit plate is an important element in the box design and is intended to close the box hermetically, sealing completely the contents. The production process prior to the introduction of $5 \mathrm{~S}$ involves machining, welding and assembly steps with elements of the soffit plate available in the workshop but not strictly subjected to any particular systematic organisational approach or lean methodology except those required legally and by the corresponding health and safety as well as quality standards which are closely followed and monitored. There is usually increased number of movement around the workshop floor and significant amount of time needed to move and store elements and the ready product.

It was believed that the usual production approach adopted would not be sufficient or sustainable for profitability, and would result in wastes, inefficiency and bottlenecks. It was important that $5 \mathrm{~S}$ be implemented from the beginning, but it was also important that time and care was taken to determine the best 'style' to implement this and to allocate time for the training of teams.

\section{Methods}

In order to deploy $5 \mathrm{~S}$ across the production process, four steps have been taken to study what adaptations will be needed and to evaluate the impact of the project on the organisation as a whole.

1. As a first step, a business model canvas for the company was created in order to better understand company positioning and activities, and to help reflect on strategy and identify the principal areas that may be affected by $5 \mathrm{~S}$ practice. The business model canvas includes key partners, activities and resources of the organisation that also impact soffit plate production. Customer relationships, segments, and channels are used to frame the value proposition. The financial aspects of this analysis are broadly developed through the cost structure and revenue streams. The canvas was created after dialogue with key internal stakeholders.

2. As a result of this dialogue, the business model canvas was complemented by an extended stakeholder analysis in order to identify the best approach to communicating kaizen and performing 5S. Both internal and external stakeholders have been considered along with their relative power and influence. The stakeholder analysis helped reveal some aspects that can be used in a SWOT and McKinsey 7S analyses, which were completed as a third step.

3. SWOT and McKinsey 7S analyses were performed in order to understand the repercussions and impact of change management that $5 \mathrm{~S}$ implementation will involve and to aid in the identification of associated risk.

4. The fourth step involved the planning and implementation of $5 \mathrm{~S}$. This consisted in a focussed literature review prior to the launch of $5 \mathrm{~S}$ to help outline the manner in which the methodology should be deployed within the company, based on the findings on the business analyses.

The collection of observations on the changes $5 \mathrm{~S}$ has had on the organisation was performed during the project by the project team.

The significance of this type of approach and the associated research is that it blends traditional business and market analysis approaches with kaizen and $5 \mathrm{~S}$ in order to facilitate their integration.

\section{Focussed Literature Review}

A review of the literature reveals a number of approaches to $5 \mathrm{~S}$ implementation. Most of them adopt blended approaches to this process and show significant creativity and innovation in their adaptations in context. A number of studies show that $5 \mathrm{~S}$ implementation results in optimisation and efficiency, and its adaptability contributes to improved quality. [MORE HERE ON NEW REFERENCE] For the purposes of this study, a set of 5 papers on case studies were utilised in order to draw out ideas and patterns for a blended approach towards generalising $5 \mathrm{~S}$ practice across an engineering company, focusing on each step of the process. 


\begin{tabular}{|c|c|}
\hline 5S Steps & Detail of Implementation Ideas \\
\hline $\begin{array}{l}\text { Sort } \\
\text { Involves sorting of materials, } \\
\text { tools, equipment and others to } \\
\text { bring order, simplify } \\
\text { inspection, reduce distraction, } \\
\text { eliminate obstacles, increase } \\
\text { space availability. }\end{array}$ & $\begin{array}{l}\text { Sureja et al. (2017) plan and divide the sorting process into sub-steps that } \\
\text { include a list of actions, resources and target outcomes for the step. The } \\
\text { removal of unnecessary items is kanbanized by red-tagging areas as well as } \\
\text { items. This visualisation methodology intends to clearly differentiate not only } \\
\text { between what remains and what is thrown out, but between what is recycled, } \\
\text { sold, relocated or disposed of. There is an added dimension of sustainability } \\
\text { practice in this approach. }\end{array}$ \\
\hline $\begin{array}{l}\text { Set / Straighten } \\
\text { Involves smoothening and } \\
\text { facilitating workflows by } \\
\text { implementing work-cell } \\
\text { design, finding and fixing the } \\
\text { best place for each item, tool or } \\
\text { piece of equipment. }\end{array}$ & $\begin{array}{l}\text { Gupta and Jain (2014) define } 5 \mathrm{~S} \text { as a step towards kaizen and develop a } \\
\text { methodology where } 5 \mathrm{~S} \text { is integrated in a continuous improvement that } \\
\text { differentiates operations as value-adding and non-value adding. Within this } \\
\text { framework, spaces, tools and work stations were examined by process walks } \\
\text { (gembas) in order to identify the problems along with their root causes, and } \\
\text { to allocate specific actions for the set stage of the holistic kaizen process. }\end{array}$ \\
\hline $\begin{array}{l}\text { Shine } \\
\text { Involves inspecting and } \\
\text { cleaning spaces, tools and } \\
\text { equipment to improve health } \\
\text { and safety, to increase } \\
\text { efficiency, to minimise or } \\
\text { eliminate waste, and prevent } \\
\text { production defects. }\end{array}$ & $\begin{array}{l}\text { Zhang and Tan (2011) develop the questions of workshop maintenance as } \\
\text { institutional priority and examine rules, regulations and standards, especially } \\
\text { as concerns industries such as electrical/electronics design and development } \\
\text { where the need for clean room facilities requires specific attention and } \\
\text { higher-level management. Machining and production environments, which } \\
\text { tend to generate more waste, are also considered. The lessons learned here } \\
\text { include clear communication of rules and regulations and well as vigilance } \\
\text { over actual implementation. }\end{array}$ \\
\hline $\begin{array}{l}\text { Standardise } \\
\text { Involves establishing } \\
\text { processes and procedures for } \\
\text { the systematic repeatability } \\
\text { with maximally similar results } \\
\text { across different operators of } \\
\text { the first three practices. }\end{array}$ & $\begin{array}{l}\text { Filho et al. (2017) initially investigate several productivity increase } \\
\text { methodologies, including "getting things done" (GTD), Pomodoro as well as } \\
\text { six sigma, but } 5 \mathrm{~S} \text { was selected due to the standardisation element, which } \\
\text { favours continuity in time and helps preserve the positive change. This study } \\
\text { notes that one of the most important factors for successful standardisation } \\
\text { was clear communication and strong interaction among team members. } \\
\text { Among the lessons learned was initial stress, resulting from change of } \\
\text { methodology and the perception of disrupting the work environment. }\end{array}$ \\
\hline $\begin{array}{l}\text { Sustain / Self-discipline } \\
\text { Involves training and } \\
\text { discipline to ensure that } \\
\text { everyone follows the } 5 \mathrm{~S} \\
\text { standards, which become the } \\
\text { basis for lean production. }\end{array}$ & $\begin{array}{l}\text { Ayabakan and Eken (2014) examine industrial application towards } \\
\text { sustainable process development and frame } 5 \mathrm{~S} \text { within a "lean manufacturing } \\
\text { house" where the purpose of } 5 \mathrm{~S} \text { is ultimately to make the process "habitual" } \\
\text { and foundational, aiming to stabilise all other improvement processes. This } \\
\text { sustainability is achieved through a combination of training to minimise } \\
\text { resistance to change and systematic application as well as celebration of good } \\
\text { results. }\end{array}$ \\
\hline
\end{tabular}

\section{Table 1 5S Implementation Examples: Summary of Key Literature}

The variety of approaches revealed by the studies in Table 1 reveal that $5 \mathrm{~S}$ can be flexibly adapted to specific company needs, taking into account all the aspects of internal and external operations. This is known to generate high levels of returns and has an indirect impact on distribution and well as customer service, creating flow and stability across workshop floor operations. (Bonilla-Ramirez et al., 2019) Some studies note that 5S or similar production maintenance approaches will impact an organisation's productivity as a result of enhanced collaborative work, improved awareness of team members' contributions, ultimately creating more synergistic environments. (Ngozag, 2020) In all cases, the changes implemented in the case studies were driven by an overarching strategy, whether this was health and safety, or improvement of team work and communication, or reducing production waste, and additional methodologies were used to strengthen the application of 5S. This shows that prior knowledge to some strategic directions, aims and goals of a company or project are essential for the success of $5 \mathrm{~S}$. Prior knowledge will be developed by the use of business analysis tools to investigate the company business model, its stakeholders and its readiness for change.

\section{Business Analyses}

\subsection{The Business Model Canvas}

The Business Model has been used to understand and analyse the current position in which NIS Ltd. operates. It will specifically examine how the company tenders for work in specific industries (cf. Table 3 presenting a Business Model Canvas for NIS Ltd.) and to analyse the nature of the various aspects of its operations. While application of $5 \mathrm{~S}$ if oftentimes considered on an everyday operations level, this case study considers that the 
introduction on a new methodology should be considered on a business development level in order to evaluate its impact across all company activities. It is interesting to note that the company subject to the present study has a long-standing history in its areas of activity and has thrived through the dramatic technological and economic changes that occurred since the last decades of the $20^{\text {th }}$ century. This shows an agile and flexible approach to market positioning and a responsible, stable approach to partnership development. Its key activities are focused on engineering projects with services and products for the nuclear sector, requiring strong expertise.

The nature of NIS Ltd.'s key activities determines core requirements for its projects which include security, safety, bespoke design, and high-precision, yet cost-effective solutions. This is also linked to its core value proposition which is centred around ISO compliance. This indicates that a $5 \mathrm{~S}$ approach would be beneficent to the company as its impact should promote the higher efficiency, timeliness and resourcefulness, ultimately resulting in better quality overall. The cost structure and revenue streams also indicate that reduction of wastes can be a positive strategy overall. A $5 \mathrm{~S}$ approach would have to principally focus on improving the value proposition.

\subsection{Stakeholder Analysis}

The stakeholder analysis presents and reflects information to determine whose primary interests should be taken into account when developing or implementing a process (Schmeer, 2020). In this case, key stakeholders have been identified and categorised in order to determine how their relative power and influence will affect the $5 \mathrm{~S}$ implementation process. Table 2 identifies and categorises stakeholders that may influence or affect the $5 \mathrm{~S}$ implementation for NIS Ltd. The stakeholders identified in this example will be the individuals/ companies/ departments that will benefit from the introduction of $5 \mathrm{~S}$ throughout the business.

\begin{tabular}{|ll|}
\hline Stakeholder & Detail \\
\hline Owner & Has the most power and influence. Provide initial funding for change implementation. \\
\hline Directors & Must OK the 5S process before any funding can be authorised. \\
\hline HSE & $\begin{array}{l}\text { The HSE is a governing body which has the power to shut down any business susceptible to } \\
\text { unsafe workplace and negligence in respect of the regulations. }\end{array}$ \\
\hline Client & Impacted by leaner manufacturing as cost savings result in lower price. \\
\hline Competitor & Has a direct influence to any business as they are the companies rival business. \\
\hline Manager & $\begin{array}{l}\text { Managers have more power and influence than employees, due to their supervisory position } \\
\text { within the company. }\end{array}$ \\
\hline Employees & $\begin{array}{l}\text { The direct workforce has a small amount of power but holds valuable influence on company } \\
\text { productivity. }\end{array}$ \\
\hline
\end{tabular}

\section{Table 2 NIS Ltd. Business Stakeholders}

Within the Business Model Canvas (Table 3), these stakeholders have a central place as part of NIS Ltd.'s value proposition either as creators or users of value. It is important, however, to determine which of these stakeholders have the most power and influence on impacting and changing the value proposition in the most favourable and sustainable manner possible. 


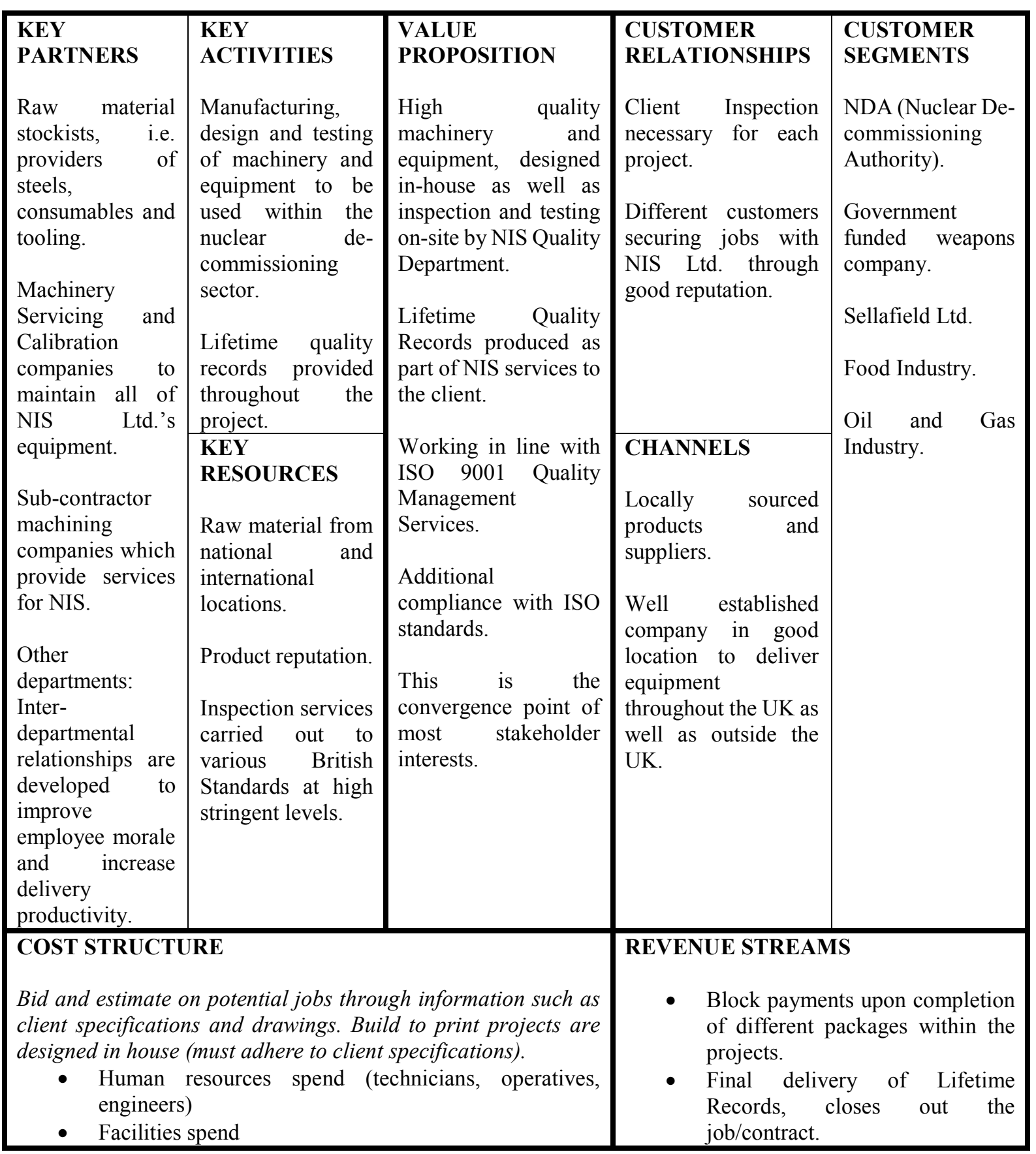

\section{Table 3 Business Model Canvas for NIS Ltd.}

Each stakeholder identified has been assessed based on their power and influence within NIS Ltd. based on a relative score, ranging between one and 10, where one reflects the lowest level and 10 reflects the highest level. Two sets of data have been gathered as follows:

- Stakeholders with the highest power score would have control over financial aspects and strategic decision-making for the future of the company.

- Stakeholders with the highest influence score would be those who have a direct impact on the methodologies and processes, as well as operations and the day-to-day activities of delivery-level personnel. 


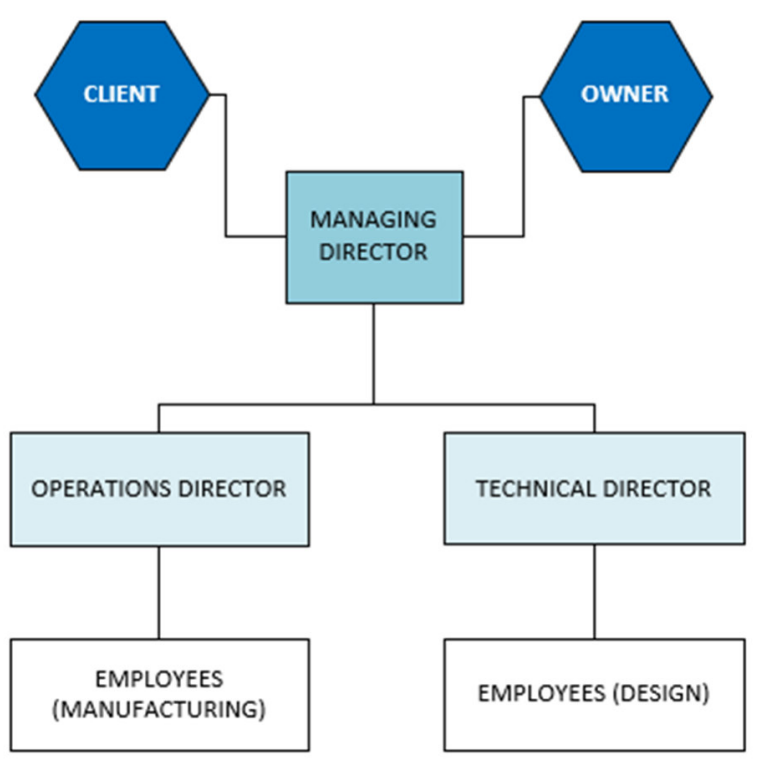

Figure 3 Organisational Structure Pre-Change

The diagrams have been produced to include the scores from both sets of data and to cross-compare the changes and implications for stakeholder interests. Prior to the $5 \mathrm{~S}$ change, this is completed relative to the organisational structure of the company pre-5S implementation. (Figure 3) It appears that the employee layout for NIS Ltd., showing key stakeholders reporting structure within the business, is a traditionally layered vertical structure, which tends to favour change management originating within leadership.

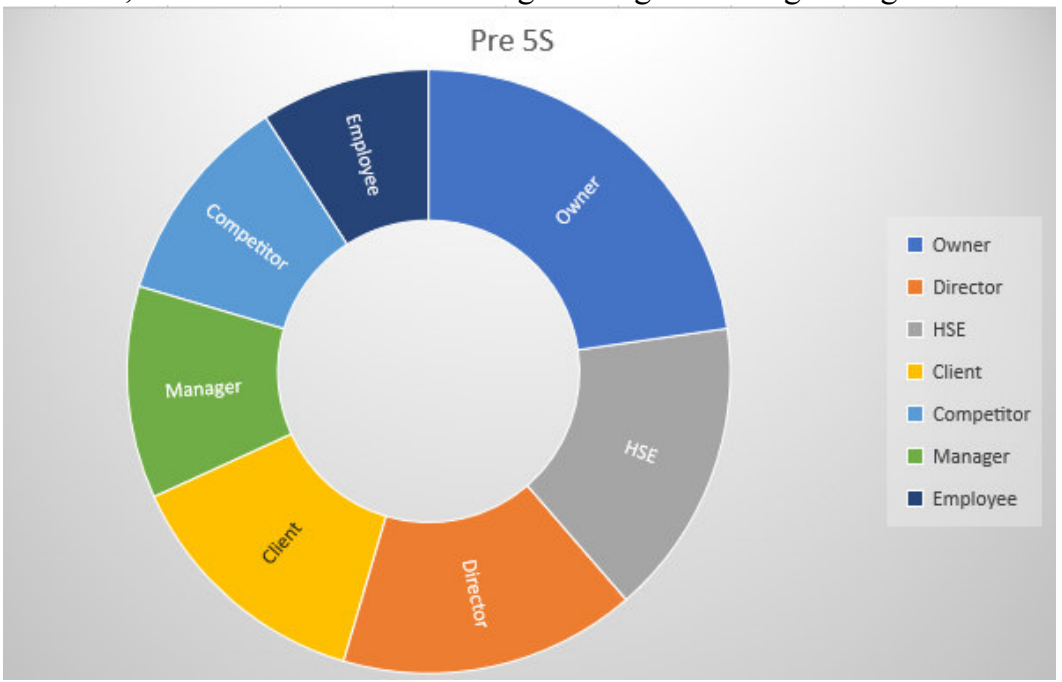

\section{Figure 4 Pre-5S Power and Influence Diagram}

It becomes evident that the owner in this case has the highest decision-making power as well as the highest influence. (Figure 4) Added to this are the power and influence of the director, which is equivalent to the upper managerial levels of the company. The Health and Safety Executive (HSE), a regulatory body, has very strong influence over decisions, especially linked to operations that may involve risk for human health and safety. These three combined possess over $50 \%$ of the power and influence within the company. While this may be important in terms of strategic decision making, one could ask the question whether it is not a good idea to increase the influence of customers and employees, especially in terms of health and safety as well as in product quality, given that they are the ones to directly benefit from any positive developments of those.

Figure 2 is based on the position NIS Ltd. are in before the implementation of 5S. It demonstrates the power and influence that each stakeholder has within the company, and provides additional insight into the distribution of strategic decision-making as well as overall management and process controls within the company. It is obvious that most stakeholder interests converge in the value proposition, while only some stakeholders have strong power and influence over its control. While this has resulted in a consistent and streamlined directive power to-date, this also shows that positive change within the lower layers of the structure could increase quality, value, and boost employee engagement as well as help improve customer relationships through utilitarian actions that are under the 
control of employee-level staff. A SWOT analysis could help further understand the impact of such a change.

\subsection{SWOT Analysis}

The development of a SWOT analysis, followed by McKinsey's 7S model for change management will delineate the impact of the $5 \mathrm{~S}$ project on the company as a whole. Bismark et al. (2018) suggest that analysis models have been the tools that most professional institutions use to evaluate overall performance of the organisation. However, in this case, the aim will be to evaluate the impact of an intended change in order to better understand its impact in the organisation before implementing it. Similar utilisation of business analysis tools for understanding the impact of a $5 \mathrm{~S}$ project has been presented by Bharambe et al. (2020) who consider the utilisation of 5S and justin-time (JIT) from the point of view of opportunities and strengths they create for organisations. For the present study, both the SWOT analysis and McKinsey's 7S models are expected to provide the opportunity to reflect indepth on NIS Ltd.'s performance as well as on aspects that may be impacted by the 5S project and the changes on employee level it will bring. These models may demonstrate some areas of the organisation as deficient, while other may be found to flourish.

The SWOT reflection (Table 4) has revealed that the opportunities created by $5 \mathrm{~S}$ implementation will increase the influence of employee-level operatives. It is expected that initiative and autonomy will create an increased awareness to health and safety, reduced production or work times and improved quality of experience. A $5 \mathrm{~S}$ project will directly impact work, which means that weaknesses will be found in case the project is seen as a leadership initiative. It will be crucial to strategically communicate the project as an employee initiative and stress the increase of personal autonomy and opportunity to show initiative that the project will bring. The impact of a mini-5S project may have unexpected positive results, i.e. could develop into training and continuous professional development opportunity. It could potentially result in a change of organisational culture and become more widely adopted. This is clearly evident in the opportunities analysis.

- With 5S, each tool and component will have its own location, making it easier to locate, thereby improving productivity.

- Employees will gain confidence in the process (Ford, 1913); knowing all items are within their vicinity, reducing waste of travel time (Wilson, 2013).

- Allows the company to gain a better understanding of the most waste-affected areas and can then improve that around the whole business (Patten, 2006).

- There is potential for improvement around the whole business and not just isolated to a single 'zone'.

- Using the methods that work well on the initial projects they can be filtered and moulded to suit other work area 'style'.

- It is important not to be narrow-minded and use the same 'style' throughout the business. Different operators may have different methods, so it is important that people tailor to suit them (Ghodrati, 2012), without straying too far from the primary objective.

\section{Table 4 SWOT Analysis (5S Implementation)}

The purpose of utilising McKinsey's 7S model (Table 5) is to better analyse NIS Ltd. in a set of categories such as: organisational structure, systems, management and leadership as well as working styles, staff, skills and training or continuous professional development opportunities, overarching organisational strategy and company shared values (Hanafizadeh, 2011). The importance of linking these seven categories together is to show that a weakness in one area can ultimately create a weakness in the remaining areas, and to link that weakness to a potential solution, which in this case is the application of a $5 \mathrm{~S}$ process.

Implementation of a new process is not to incite stricter rules to follow, but to improve the current situation one stage at a time until the whole business is connecting the dots, and working towards one common goal. It is also important to note that using these models with special attention to NIS Ltd.'s organisation culture will bring 
greater success, development and growth to the business (Bismark et al, 2018). This is in conjunction with Akyeampong (2016) who comments that the growth and success of organisations largely depends on the organisation's culture. McKinsey's 7S thus reveals that the focus of the 5S project, apart from the concrete application of the methodology, should be strongly oriented towards organisational culture and any communication and continuous professional development efforts should target the culture aspect above all.

\section{Strategy}

Ensure that the stakeholders are involved in all aspects of future change, this will provide the correct backing by management.

Ensure that all lessons learned from every aspect are taken into all upcoming work, filtering out negative points and improving the processes to create a smooth flowing future for the company.

Embed into future strategy the importance of Learning from Experience meetings. Use them before, during and after any current project.

\section{Structure}

Structure of a workshop may be adaptable to suit the client needs.

Contamination between materials can have a damaging effect on quality, therefore, using $5 \mathrm{~S}$ to ensure that everything has a place and everything is in its place, will maximise productivity and increase reputability.

Environmental factor based on the layout, means that minimal waste is produced; as each area has a requirement to be clean and organised.

\section{Systems}

Each process stage for the Soffit Plate project has been timed in order to maintain an average for each operator.

The processes are flowed in such a way to ensure that operators have sufficient work, therefore, reducing the risk of downtime, reducing the risk of profit loss.

The employees are a highly dependable component in the business system. They provide data for company to base their delivery times and manufacturing improvements. They are the true cogs of the machine.

\section{Shared Values}

- MAKING A PROFIT FOR THE COMPANY, IN ORDER TO RE-INVEST INTO THE BUSINESS.

- INCREASED REPUTATION FOR THE COMPANY ACROSS THE SECTOR.

- CONTINUOUS IMPROVEMENT FOR FUTURE TRAINING AND PROJECTS.

- $\quad$ lEAN MANUFACTURING PROCESSES TO CREATE BETTER WORKFLOW AROUND THE COMPANY.

- $\quad$ SAFE SYSTEMS OF WORKING TO ENSURE EMPLOYEE AND EMPLOYER SAFETY, AS BEING THE TOP PRIORITY.

\section{Skills}

Each operation requires a high level of skill and experience, although with batch production it is much simpler to set up a process and train operators to follow that process, in order to recreate each component to the correct standard.

Any training that is required must be carried out to improve the sustainability of the project and reduce the risk of untrained operators producing incorrect work.

An opportunity to train the workforce in 5S implementation, Lean Six Sigma training for specialised areas. Industry Relevant techniques can be applied. Cost of training and re-educating staff members is always worthwhile to the business.

\section{Staff}

Employee morale is the most important factor in terms of productivity increase.

There are channels in place to ensure that employees can have a say on the change/ improvements structure as well as attending Learning from Experience (LFE) meetings to improve future working relationships.

Employees can play a vital role in the influence change of a business, therefore, is it critical to ensure that they feel like valuable members of the organisation.

\section{Styles}

Managerial styles differ from each team leader. Fabrication/ Assembly/ Machining. The Team leaders for each of these teams utilise different styles.

This has a knock-on effect on the team individuals as the project is not working in harmony. Some can oppose managerial styles; it is important to encourage a good working relationship with the team.

There are many change styles in which companies can adopt and adapt towards. One being the utilisation of $5 \mathrm{~S}$, this can directly impact profit and safety.

Table 5 McKinsey 7S Analysis 


\section{Change Implementation}

Figure 5 displays an example of the $5 \mathrm{~S}$ project that has been implemented at NIS Ltd. This began with the company's welding consumable storage area, which is considered to be a pivotal space for the soffit plate production. This area, due to the nature of its activities, is well controlled, as there may be undesirable effects of the natural environment on welding electrodes. Decluttering the area has led to improved traffic through the facility as well as reduced time for finding, borrowing and replacing tools. Overall, this has reduced the time for producing soffit plates as more time overall was spent on core activities for the project.
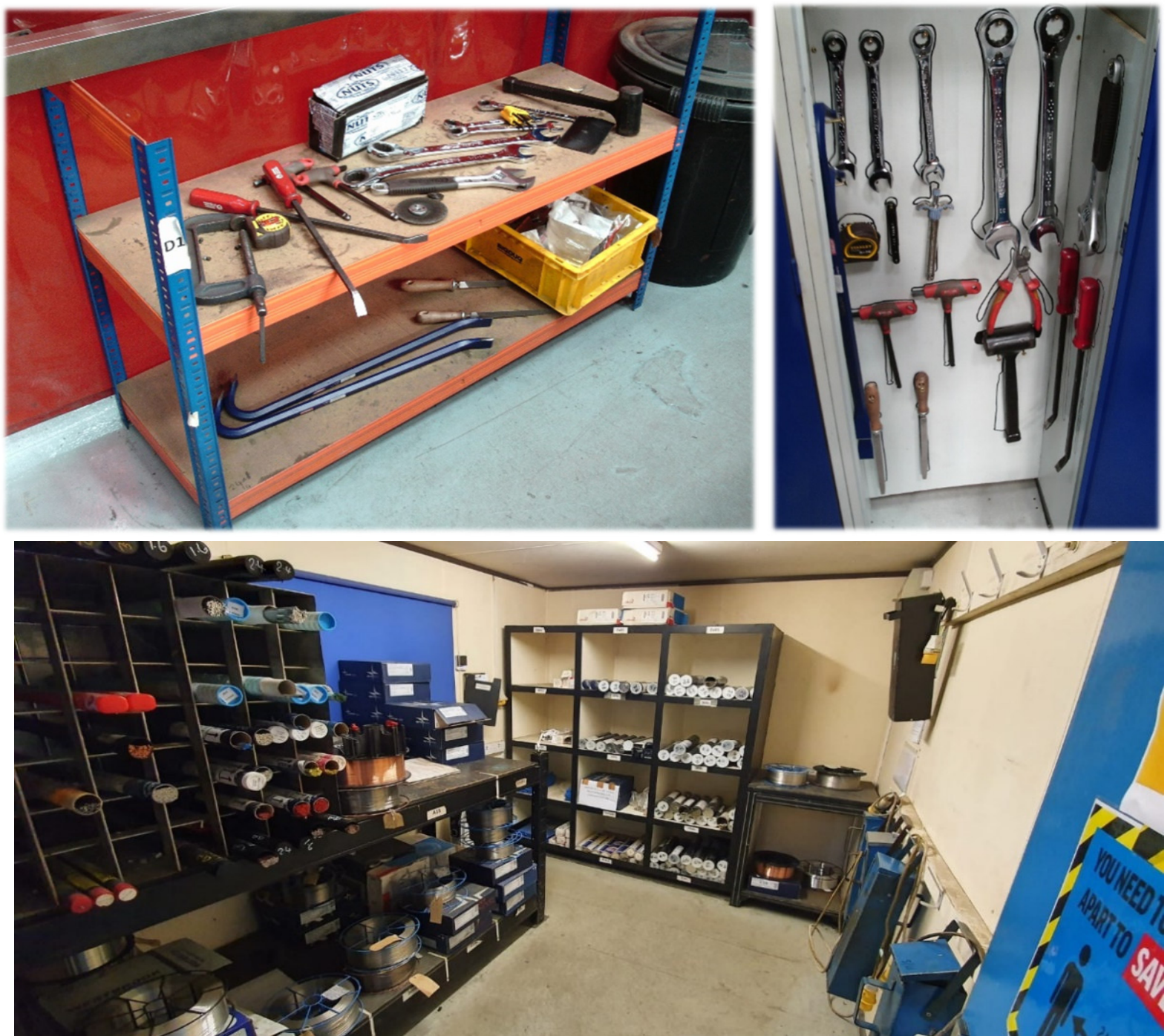

\section{Figure 5 5S Example of NIS Ltd.'s welding consumable cupboard}

Lixia and Bo (2008) propose that to ensure 5S becomes a culture within the workplace, a committee between eight and ten staff members should be produced. Such a committee will help define a strategy and action plan to drive change throughout the organisation. This is also supported by Grover (2012) who infers that 5S is implemented by establishing a cross-functional team. A team to conduct regular audits and frequent meetings, to hold people accountable for actions, has been selected to enforce a departmental approach. The committee consists of a sponsor, area champion as well as team leaders who oversee the spaces depicted on Figure 5 and maintain the continued implementation of $5 \mathrm{~S}$.

A first step to implement change has been to promote an employee into a change and improvement managerial position, with the sole focus being based on leading change within the business. The individual would report directly to the Managing Director, as demonstrated in Figure 6. This reduces any risk of impact from the director's opinion. However, it would be difficult for the manager to implement the $5 \mathrm{~S}$ change across all areas and involve all other employees directly. Therefore, the introduction of employees specifically trained in Lean Six Sigma intends to help deploy the methodology across the facility and improve the communication between managers and employees. This will also create continuous professional development opportunities for employees.

The organisational structure post-change includes the introduction of change agents who are Lean / Lean Six Sigma trained and who know well the daily routines and environment of the facilities within which the change 
will be operated. While the vertical structure is not fully disrupted, it now allows for improved access of employees to management levels through the medium of continuous improvement and favours dialogues towards this goal.

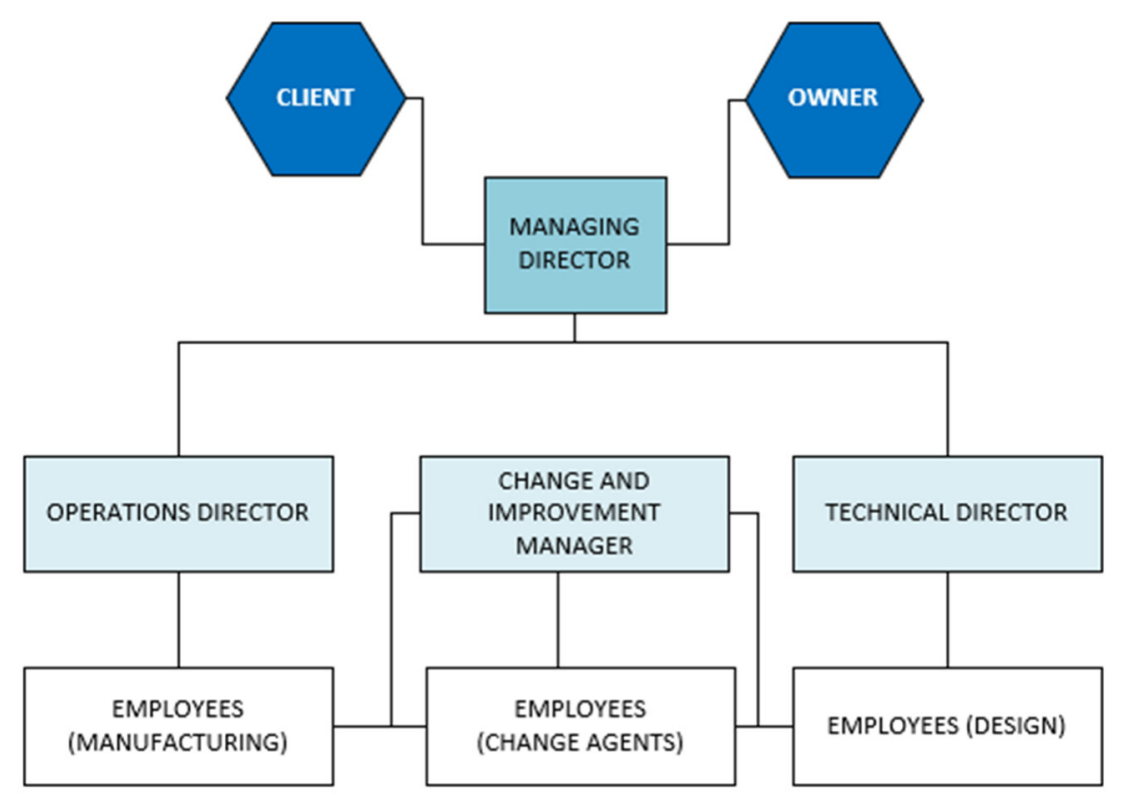

Figure 6 Revised Employee Layout Diagram for NIS Ltd.

The Power and Influence diagram (Pre-5S Figure 7) has changed dramatically since introducing 5S into the business, as revealed in Figure 7. Some key changes can be easily observed. For example, the Health and Safety Executive (HSE) still controls a vast amount of power within the business as all teams are bound by legal requirements, but with the introduction of $5 \mathrm{~S}$ the team has taken ownership of the kind of measures taken and the manner of their deployment, which has created greater freedom overall. In addition, if the organisation is able to showcase the improvements made during the $5 \mathrm{~S}$ and simplifying the system, the HSE will have an increased trust gained in the approaches and methods adopted by the company. The simplicity of the system makes safety become the everyday normality. The perception of health and safety being an obligation and a requirement to which all are bound by law has gradually become integrated in a sense of control over the production process. Employees are now focussed on the impact of $5 \mathrm{~S}$ on facility of movement and retrieval of tools, while health and safety improvements have become the natural consequences of the process. Grover (2012) suggests that Safety can be the ' 6 th $S$. Grover (2012) also implies that key components of the $5 \mathrm{~S}$ philosophy are safety measures and good housekeeping. They have to be maintained and ensure that optimal organisation is sustained in the long run. This is further supported as a study indicating that the $5 \mathrm{~S}$ technique is an effective way to improve health and safety standards, environmental performance and housekeeping (Rahman et al, 2010).

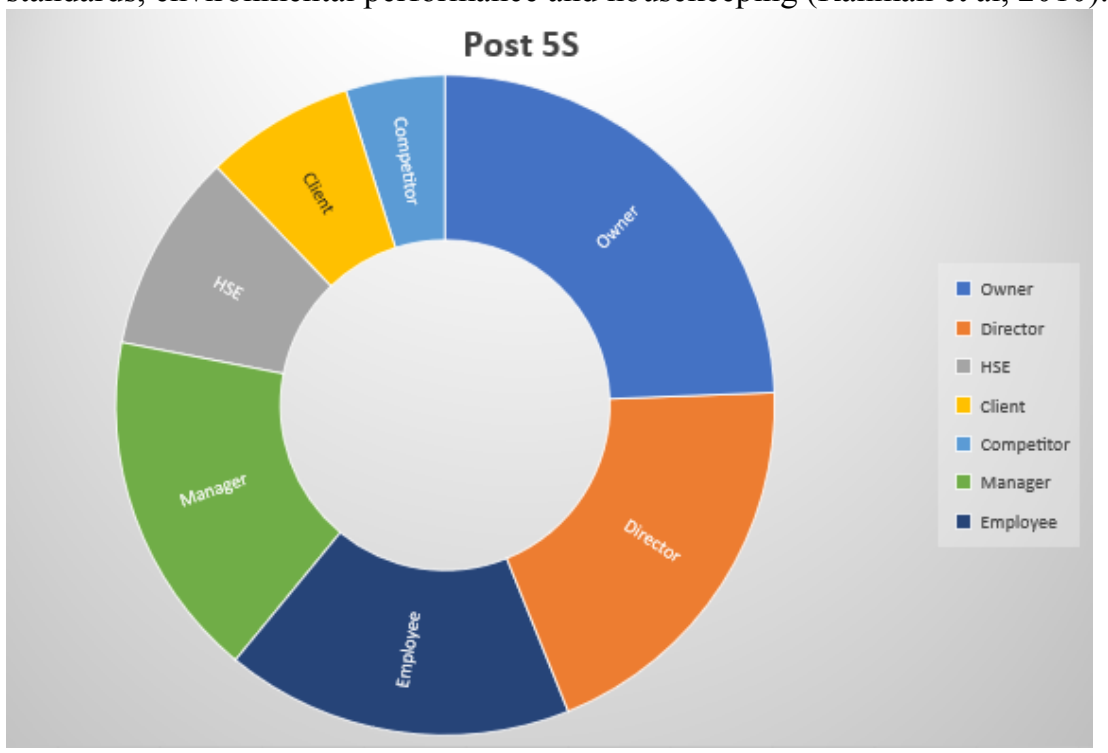

Figure 7 Post-5S Power and Influence Diagram

When examining Figure 4 and Figure 7, it is also clear that a notable change occurs for the competitors. A 
reason for this would be because the business has out-performed the competition in all areas of capability. The $5 \mathrm{~S}$ system has embedded itself well throughout the company and areas are starting to see minor improvements to the everyday routine. This has had a positive impact on the power and influence of employees as well as on the relative standing of the organisation as a whole on the market. Key managers and staff are considering Lean and Lean Six Sigma certification, which also indicates engagement in continuous professional development.

\section{Business Impact}

Naturally, there will be a resistance when implementing any change, and Lixia and Bo (2008) state that only 5\% of staff will embrace the change, $90 \%$ of "fence sitters" will look for leadership and $5 \%$ of "concrete heads" will resist. The strong leaders will create progression and as a company, the change should be recognised and rewarded which will ensure the $90 \%$ category will gradually accept the change or adjust to it, and merge with the top 5\% bracket.

\subsection{Continuous Professional Development}

In the case of the Soffit Plate Project, the effort to promote and sustain the change has resulted in staff training and development, which helped bring the teams together and created more unity among individuals. To keep the business sustainable, further education of employees will be required in this case. NIS Ltd. is an engineering company working on projects with high health and safety impact as well as with a strong focus on staying up to date with technology trends. To keep its relevance, the 5S team working on the Soffit Plate Project engaged in continuous professional development. As a result, a 5S Nuts and Bolts game was produced for company-wide training, using surplus mechanical fasteners from the completed project. The game follows simple $5 \mathrm{~S}$ methodology to show in practice and visually the amount of time saved and the greater consistency across operators when $5 \mathrm{~S}$ is applied.

Filho et al. (2017) suggest that the low-cost nature of the 5S method is an adequate start in quality improvement. However, Gomes, Lopes, Carvalho (2013) propose that a benefit of 5S is reducing cost and better use of materials in a manufacturing perspective. There is a positive correlation between introducing $5 \mathrm{~S}$ and reducing costs to the business. Steering the process away from the high-power, high-influence stakeholders, will allow the employees to feel the implementation of change as their own success. It will positively affect their working life as well as the future reputation of the company.

\subsection{Waste Management}

Waste is an unfortunate product of most processes, but it can be reduced and also re-used if controlled correctly. Andanari \& Goto (2013) imply that successful implementation of a recycling system may not only create a new source of income but also help to protect the environment and health. In support of this, Zhou et al (2018) claims that a proper implementation at organisational level requires the waste management model to consider environmental, economic and social factors to provide better waste treatment options than just incineration or landfills.

Understandably, waste is not just limited to material and consumables. Waste can also be stated as time, or excessive time spent looking for tools or components as well as distractions from external influences (i.e. talking too much, excessive time spent on breaks and also the use of phones in the workplace) (Lin, 2019). As this waste is an attribute to only human operators, it is important to find a balance with the right amount of discipline. At NIS Ltd. phones are forbidden from being on the shop floor as these pose a security risk, given the type of confidential projects on site. This is supported by Bromwich (2016) who states that risk associated with the use of smart phones to store images in industry can be a security risk. With the particular industry that NIS Ltd. operates in, the use of cameras could potentially endanger national security.

$5 \mathrm{~S}$ tools can help reduce waste and boost productivity and having the correct equipment on hand will reduce time spent looking for items. In addition to this, having a system where the use of tools is monitored will ensure that equipment will be accounted for and be checked for defects on return. This will simplify the process in reordering tools when they become defected, as the business are aware of what inventory they already possess.

\section{Conclusions and Future Work}

For NIS Ltd., with the introduction of $5 \mathrm{~S}$, there will be a positive impact almost immediately at a small cost. However, the small cost will turn into profit within a matter of time once implemented and sustained correctly. It is recommended that NIS Ltd. focus on changing outdated $20^{\text {th }}$-century culture and look towards a future that will see continuous change and improvement as intrinsic to organisational growth. The importance of producing a sustainable culture where stakeholders strive, while employees thrive can be a sustainability goal min- to longterm.

The most important cog in the machine is the employee. Driven by the cog of the powerful and influential stakeholders, supported by the introduction of a lean culture, an employer must ensure that the system works 
smoothly to support core service, which drives the business. "If employees are to prosper in this environment, companies must offer them a continuing variety of challenges. That way, they will feel they are honing their skills and are valued for the many kinds of expertise they have attained." (Womack, Jones and Roos, 2007) A key challenge for employees here, and a fundamental area to focus on, is additional 5S training and a precursor to Lean Six Sigma methodology deployment. Training of staff will help the business become more sustainable, while further demonstrating the benefits of continuous improvement both organisationally and in terms of personal professional development. Ideally, all staff will be trained in basic lean manufacturing techniques, allowing the method to flow throughout the core of the business. Including this in the company business plan will also ensure that the goal is not undermined and leadership buy-in is maintained.

Future work in this respect can focus on the manner in which Lean Six Sigma or lean manufacturing methods will be implemented across the organisation and the various projects resulting from this effort. Further studies can look at human capital projects as well as at learning of other workshop areas. The introduction of Kanban systems can be another aspect to develop and study. The combination of 5S and Kanban systems together can further be supported by the gradual implementation of process walks until a complete lean methodology is progressively applied. Continued future work can also focus on implementing similar bespoke 5S practice into the operations of another organisation to determine whether the effects are similar. Further studies should also investigate personnel training and education needs in order to sustain $5 \mathrm{~S}$ practice.

\section{References}

ANDARANI, P. \& GOTO, N. 2013. Potential e-waste generated from households in Indonesia, using material flow analysis. Available from: https://ink.springer.com/article/10.1007/s10163-013-0191-0 Journal of Material cycles and Waste Management 16 pp. 306-320 (Accessed 29/10/2020)

AKYEAMPONG, E. O. 2016. Ethical and Principled Leadership, Fasteens Publisher $2^{\text {nd }}$ Edition. Available from: http://www.ijrbem.com/doc/60.pdf (Accessed 12/11/2020)

AYABAKAN, M. EKEN, Ö. 2014. Creating 5S climate at the shopfloor, Proceedings of PICMET '14 Conference: Portland International Center for Management of Engineering and Technology; Infrastructure and Service Integration, Kanazawa: Japan, pp. 1907-1928.

BHARAMBE ET AL. 2020 Implementation of 5S in Industry: A Review, Multidisciplinary International Research journal of Gujarat Technological University, vol. 2, no. 1, ISSN: 2581-8880

BISMARK ET AL. 2018. Utilising McKinsey 7S Model, SWOT Analysis, PESTLE and Balance Scorecard to Foster Implementation of Organisational Strategy. Available from: http://www.ijrbem.com/doc/60.pdf (Accessed 12/11/2020)

BONILLA-RAMIREZ, K. A. et al. 2019. Implementation of Lean Warehousing to Reduce the Level of Returns in a Distribution Company, IEEE International Conference on Industrial Engineering and Engineering Management (IEEM), pp. 886-890, doi: 10.1109/IEEM44572.2019.8978755.

BROMWICH, M AND R. 2016. Privacy Risks when using mobile devices in health care. Available from: https://www.ncbi.nlm.nih.gov/pmc/articles/PMC5008929/ (Accessed 16/11/2020)

DOUGLAS, A. 2002. Improving manufacturing performance. Quality Congress. ASQ's Annual Quality Congress Proceedings. Vol. 56, pp. 725-732 (Accessed 05/11/2020)

DYSON, R.G. 2004. Strategic Development and SWOT Analysis at the University of Warwick. Vol. 152, Issue 3, pp. 631-640 Available from: https://www.sciencedirect.com/science/article/abs/pii/S0377221703000626 (Accessed 12/11/2020)

FILHO, W, V. BRTIO, A. L. de. CRESTANA. B, Z. and SANTOS PRADO. M. Dos. 2017. Implementing the $5 S$ Methodology to create a new culture. IEEE Technology \& Engineering Management Conference (TEMSCON), Santa Clara, CA, 2017, pp. 400-403 (Accessed 22/10/2020)

WILSON, J. 2013. Henry Ford vs. Assembly line balancing. Available from: https://www.tandfonline.com/doi/abs/10.1080/00207543.2013.836616 (Accessed 26/11/2020)

GHODRATI, A. ZULKIFLI, N. 2012. A review on 5 S Implementation in Industrial and Business Organisations. Available from: https://pdfs.semanticscholar.org/132f (Accessed 26/11/2020)

GOMES, D.F. LOPES, M.P. CARVALHO, C.V.de. 2013. Serious Games for Lean Manufacturing: The 5 S Game. IEEE Revista Iberoamericana de Tecnologias del Aprendizaje, vol. 8, no. 4, pp. 191-196, Nov. 2013 (Accessed 22/10/2020)

GROVER, J. 2012. 5S Workplaces: When Safety and Lean Meet. [online] Available from: https://www.ehstoday.com/safety/article/21915202/ (Accessed 29/10/2020)

GUPTA, S. JAIN, S. K. 2014 The 5S and kaizen concept for overall improvement of the organisation: a case study International Journal of Lean Enterprise Research, vol. 1, no. 1, pp. 22-40

HANAFIZADEH, P. 2011. A McKinsey 7S Model-Based Framework for ERP Readiness Assessment. Available from: https://www.igi-global.com/article/content/60403 (Accessed 12/11/2020)

HUBBARD, R. 1999. Case Study on the 5S Program: the five pillars of the visual workplace. [online] vol. 20, p. 
24 (Accessed 26/11/2020)

HO, S.K.M. CIRCMIL, S. FUNG, C.K. 1995. The Japanese 5 S Practice and TQM training. Training for Quality. Vol. 3, No 4. Pp. 19-24. (Accessed 05/11/2020)

HO, S.K.M. 1998. 5S Practice: a new tool for industrial management. Industrial management and data systems vol. 98, pp. 55-62 (Accessed 26/11/2020)

KOBAYASHI, K. GAPP, R. FISHER, R. 2008. Implementing $5 S$ within a Japanese context: An integrated management system. Emerald Insight 0025-1747 pp. 565-579. Available from: https://pdfs.semanticscholar.org/19f8/78a95a200369a039a2e53f64a09508ef1687 (Accessed 05/11/2020)

LIXIA, C AND BO, M. 2008. How to make 5S a culture in Chinese Enterprises. 2008 International Conference on Information Management, Innovation Management and Industrial Engineering, Taipei, 2008, pp. 221-224 (Accessed 22/10/2020)

LIN, T. 2019. Smartphones at Work: A Qualitative Exploration of Phycological Antecedents and Impacts of workrelated Smartphone Aependency. Available from: https://journals.sagepub.com/doi/full/10.1177/1609406918822240 (Accessed 16/11/2020)

MIDDLETON, A. 2019. First Man In. $2^{\text {nd }}$ Edition. Harper Collins Publishers, London, UK. p. 259

NGOZAG, L. A. et al. 2020. The Need for an Effective Collaborative Production-Maintenance Approach to Improve Productivity, Industrial Engineering Letters, Vol. 10, Issue 3, DOI: 10.7176/IEL/10-3-04

PATTEN, V. 2006. A second look at 5S. Quality Progress Vol 39 p. 55

PLAUTUS, M, T. c. 200BC. "You must spend money to make money". [online] Available from: https://www.inspirationalstories.com/quotes/titus-maccius-plautus (Accessed 05/11/2020)

RAHMAN ET AL. 2010. Implementation of 5 S practices in the Manufacturing companies. American journal of Applied Sciences pp. 1182-1189 (Accessed 26/11/2020)

SARI ET AL. 2017. An economic analysis of a system wide Lean approach. Available from: https://www.ncbi.nlm.nih.gov/pmc/articles/PMC5543735/ (Accessed 26/11/2020)

SCHMEER, K. 2020. Stakeholder Analysis Guidelines. [online] Available from: https://www.who.int/workforcealliance/knowledge/toolkit/33.pdf (Accessed 15/10/2020)

SUKDEO, N. 2017. The application of $6 S$ methodology as a lean improvement tool in an ink manufacturing company, IEEE International Conference on Industrial Engineering and Engineering Management (IEEM), pp. 1666-1671, doi: 10.1109/IEEM.2017.8290176.

SUREJA, J. V. et al. 2017 Application of 5S Methodology in Small Scale Casting Industry, Proceedings of 2nd International Conference on Emerging Trends in Mechanical Engineering, February 24th - 25th, G H Patel College of Engineering \& Technology, V V Nagar - 388120, Gujarat, India ISBN: 978-93-84659-77-6

OSADA, T. 1991. The 5S's: Five Keys to a Total Quality Environment. Asian Productivity Organisation, Tokyo, Japan. (Accessed 05/11/2020)

VIRANDA D. F. et al. 2020. 5S Implementation of SME Readiness in Meeting Environmental Management System Standards based on ISO 14001:2015 (Study Case: PT. ABC). IOP Conference Series: Materials Science and Engineering, 722 012072, Available from https://iopscience.iop.org/article/10.1088/1757899X/722/1/012072/meta (Accessed 25/05/2021)

VIPULKUMAR C. P. et al. 2014. International Journal of Engineering Research and Applications www.ijera.com ISSN : 2248-9622, Vol. 4, Issue 3 (Version 1), pp.774-779

WOMACK, J. JONES, D. ROOS, D. 2007. The Machine that changed the world. $2^{\text {nd }}$ Edition. Simon \& Schuster. London. pp. 7 (Accessed 24/11/2020)

ZHANG, S. Tan, Y. 2011. Defects and Improvement of 5S Implementation in the Workshop of MTO Electronic Assembly Industry at the Pearl River Delta Economic Zone, International Conference on Management and Service Science, Wuhan: China, pp. 1-4, doi: 10.1109/ICMSS.2011.5999274.

ZHOU Z. CHI, Y. DONG, J. TANG, Y. 2018. Model development of sustainability assessment from a life cycle perspective: A case study on waste management systems in China. Available from: https://www.researchgate.net/publication/328855875 Journal of Cleaner Production 210 (Accessed $29 / 10 / 2020)$ 